\title{
DC-Cholesterol Liposome
}

National Cancer Institute

\section{Source}

National Cancer Institute. DC-Cholesterol Liposome. NCI Thesaurus. Code C1604.

A cationic cholesterol derivative mixed with dimethylaminoethane-carbamoyl and sonicated to form small unilamellar vesicles that can complex with DNA, DNA/protein complexes and other drug complexes and mediates the delivery into the cytosol from the endosome compartment. $(\mathrm{NCl})$ 